\title{
HELP WANTED IN NEW ZEALAND: THE ANZ BANK JOB ADVERTISMENT SERIES
}

\author{
Brian Silverstone \\ Economics Department \\ University of Waikato
}

\begin{abstract}
The ANZ Bank publishes a monthly count of the number of job advertisements appearing in New Zealand newspapers and, more recently, internet sites. It is New Zealand's de facto vacancy or help-wanted series. Apart from its role in economic commentaries, there is very little published research using this data. This paper is a preliminary attempt to remedy this omission. It covers descriptive aspects of the ANZ job ads series including the vacancy rate, the hiring rate, regional characteristics and proxy vacancy series. This is followed by an outline of the vacancy-unemployment (Beveridge curve) and hiring frameworks and some initial econometric work. Overall, the paper highlights the importance of the vacancy rate and the hiring rate in any assessment of labour market conditions in New Zealand.
\end{abstract}

\section{Introduction}

In 1990, the ANZ Banking Group began a monthly count of job advertisements appearing in the main New Zealand newspapers. The initial coverage of Auckland, Wellington and Christchurch newspapers was extended to four other regions (Waikato, Hawke's Bay, Manawatu and Otago) in 1994. Since 2000, internet job ads from several major sites have also been published.

\begin{abstract}
Although the ANZ 'help-wanted' series is just a raw count - multiple jobs within one advertisement count as one job, repeated ads within the same month are included and there is no separation of regional and national job ads within each newspaper - the series is interesting for several reasons. First, it is monthly data on a real variable, in this case anticipated hiring or demand for labour. Such data are relatively scarce in New Zealand. Secondly, it is published promptly and usually within a fortnight of the previous month. Thirdly, it is a useful indicator of economic activity in general and labour market conditions in particular. Fourthly, it represents actual expenditure by firms willing to commit themselves to the relatively costly process of preparing advertisements, conducting interviews, training, mentoring and associated costs. Finally, as successful hiring requires both vacancies and applicants, the job ads series is a reminder that vacancy rates should be considered alongside employment, unemployment and participation rates.
\end{abstract}

In the absence currently of any official New Zealand vacancy statistics, the ANZ job ads series has become the de facto New Zealand vacancy series. An official vacancy series was discontinued in 1981, while its successor ceased in 1997. Another official series was discontinued in 1990. As a result of these discontinuities and related measurement issues, some authors (for example, Chapple 1995 and Hicks and Chin 1984) constructed proxy series for New Zealand vacancies. More recently, following a review of vacancy survey models and user needs, the Department of Labour (2003) published a monthly count of New Zealand job advertisements by occupation. This micro-focused series should complement the macro-focused ANZ series.

Apart from its role in economic commentaries, there is very little published research using the ANZ job ads data. This paper is an initial attempt to remedy this omission. The next section considers descriptive aspects of the series including its regional characteristics and relationship to selected proxy vacancy series. This is followed by an outline of the vacancy-unemployment (Beveridge curve) and hiring frameworks and some initial econometric work.

\section{The ANZ Bank Job Ads Series}

Figure 1 shows the number of economy-wide job advertisements from 1990:1 to $2004: 3$ using quarterly averages of monthly data. The number of quarterly advertisements has ranged from 10,000 (in 1991) to 34,000 (in 2004). The series is asymmetrical with 'advertisement recovery periods' lasting longer than recessionary periods. Internet job ads, shown separately in Figure 1, increased from a quarterly average of around 10,500 (in 2000) to 13,500 (in 2004) - a 30 percent change. Newspaper ads, on the other hand, increased by just 10 percent over this same four-year period. Electronic ads now represent around 30 percent of newspaper ads and rising. The ANZ Bank recognises the difficulty of combining electronic and paper ads. Work in this paper, however, suggests that this is a worthwhile task. 
Figure 1: National Job Ads 1990-2004

Number, Quarterly, March Years

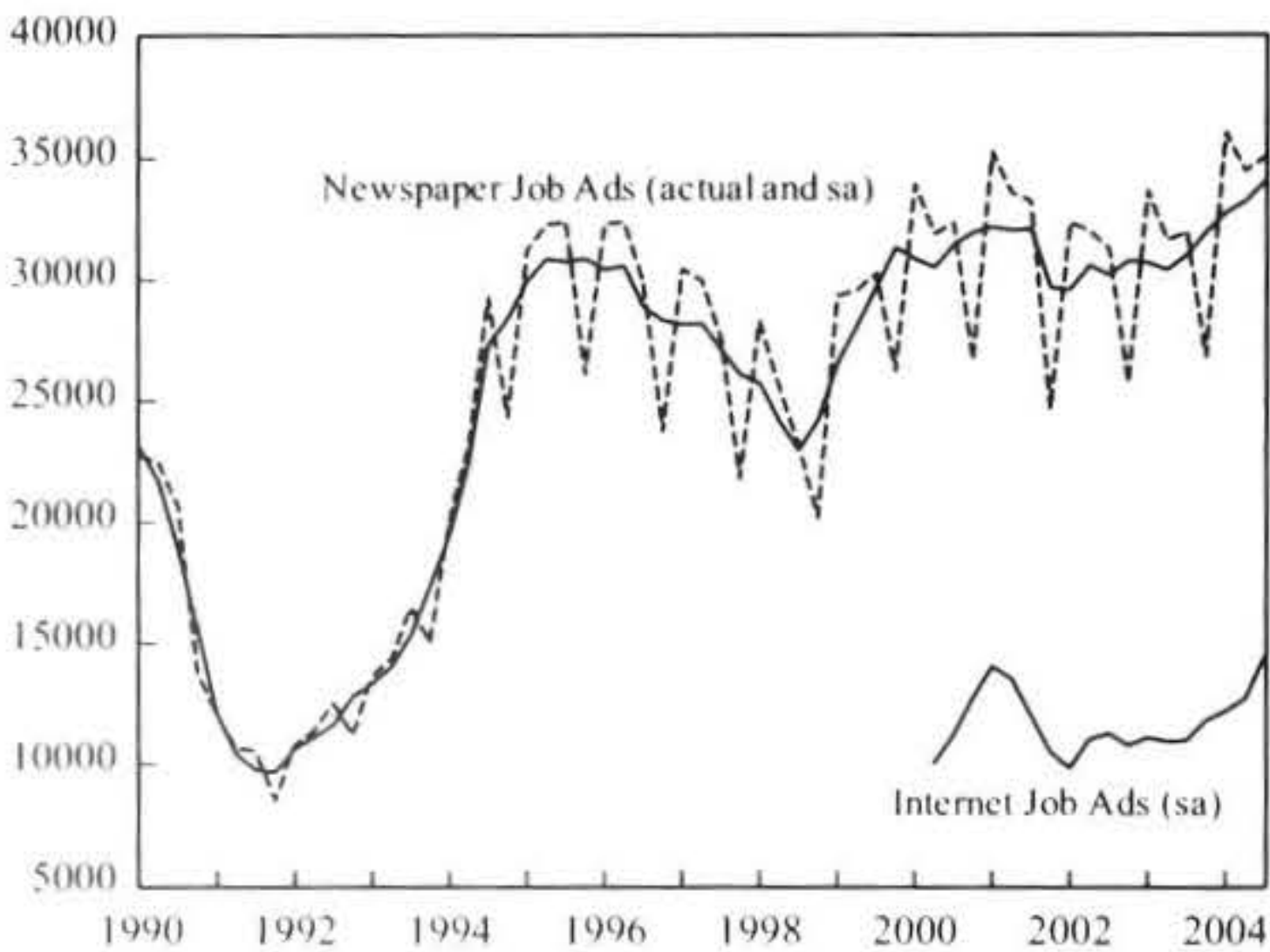

Source: ANZ Bank Job Ads

Table 1 shows a selection of unweighted descriptive statistics for the seven regions and New Zealand-wide from 1994:3 to 2004:3. (Internet advertisements are excluded), Auckland, Wellington and Christchurch newspapers typically account for over 80 percent of job advertisements. There are regional variations in both correlations with total New Zealand advertisements and in skewness (for example, Auckland is negatively skewed relative to Christehurch).

Figure 2 shows quarterly help-wanted data, converted to indices, for the three main cities (Auckland, Wellington and (hristchurch) from 1990:1 to 2004:3. There are clear regional differences in these time series. As Auckland typically comprises 55-60 percent of total job ads, its index tends to follow the New Zealand-wide index (not shown). Christchurch's index has been consistently above the New Zealand-wide outcome, while Wellington's index has been lower and flatter.

What could explain the surge in Canterbury job vacancies since 1999? An increase in the proportion of national advertising in Canterbury newspapers? Perhaps. Higher economic growth in Canterbury? Very likely. According to the National Bank's regional activity index, annual average growth in Canterbury was half a percentage point higher than Auckland over the entire period (1990-2004) and one percentage point higher than Wellington.
Figure 2: Regional Job Ads 1990-2004

Seasonally Adjusted, Quarterly, March Years

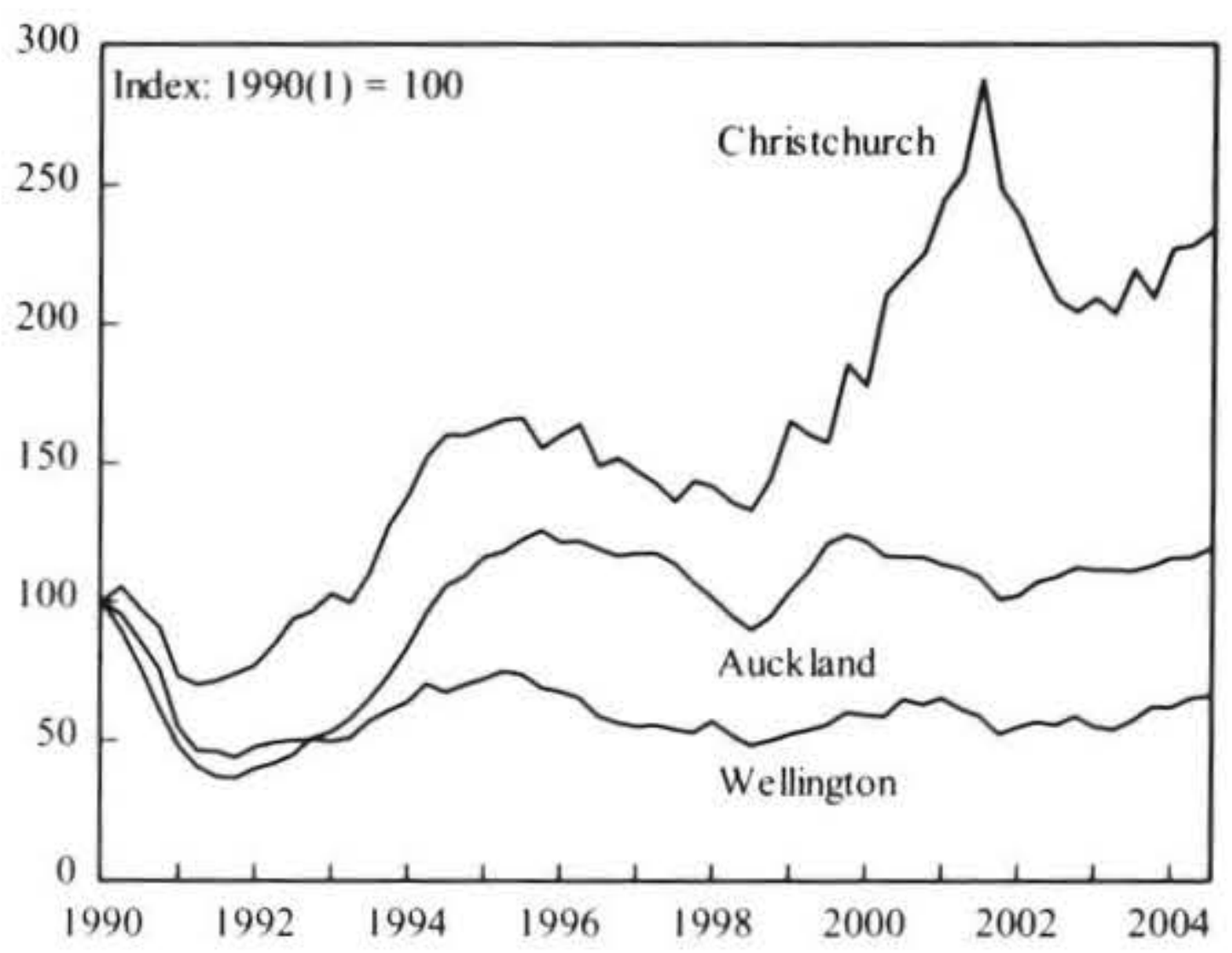

Source: ANZ Bank Job Ads.

\section{ANZ Job Ads Compared to Proxy Series}

The ANZ job vacancy series is 'help-wanted' data rather than a true vacancy series derived in a similar manner to, say, unemployment data from a household labour force survey. (Issues associated with using help-wanted data as a proxy for actual vacancies are discussed in Abraham 1987 and Zagorsky 1993, 1998). It is useful, then, to compare the job ads series with other vacancy-type measures. We consider briefly two NZIER Quarterly Survey of Business Opinion (QSBO) measures and a gross flows measure from the Household Labour Force Survey.

A QSBO question asks respondents: "What single factor, if any, is most limiting your ability to increase your production?' 'Labour' is one of the six answers. (The others are sales, materials, finance, capacity and 'other'). Figure 3 plots the vacancy rate against the percentage of firms replying that labour is the single most limiting factor constraining production. (The vacancy rate is defined in this paper, unless otherwise stated, as the ratio of newspaper and internet job ads combined to the labour force). The two series conform relatively well apart, perhaps, 2002 and 2003, when the labour constraint intensified relative to the vacancy rate. The correlation of the constraint with the vacancy rate (including and excluding internet ads) is 0.78 and 0.59 , respectively.

Table 1: ANZ Bank Job Ads Series 1994-2004

Descriptive Statistics, Actual, Quarterly

\begin{tabular}{lrrrrrrrr}
\hline & Akl & Wel & CCh & Waik & HBay & Man & Otago & NZ \\
\hline Mean & 16.743 & 3,571 & 4,349 & 2,348 & 837 & 727 & 1,150 & 29,725 \\
Ratio of Mean to NZ & $56 \%$ & $12 \%$ & $15 \%$ & $8 \%$ & $3 \%$ & $2 \%$ & $4 \%$ & $100 \%$ \\
Correlation with NZ & 0.86 & 0.78 & 0.69 & 0.84 & 0.61 & 0.83 & 0.70 & 1.00 \\
Skewness & -0.81 & 0.07 & 0.57 & 0.22 & 0.80 & 0.23 & 0.32 & -0.57 \\
\hline
\end{tabular}

Nole: $\mathrm{Akl}=$ Auckland, Wel $=$ Wellington, $\mathrm{CCh}=$ Christchurch, Waik = Waikato, $\mathrm{Man}=$ Manawatu. Soruce: ANZ Bank Job Ads. 


\section{Figure 3: Labour Constraint and Vacancy Rate 1990-2004}

Quarterly, Seasonally Adjusted, March Years, Percent

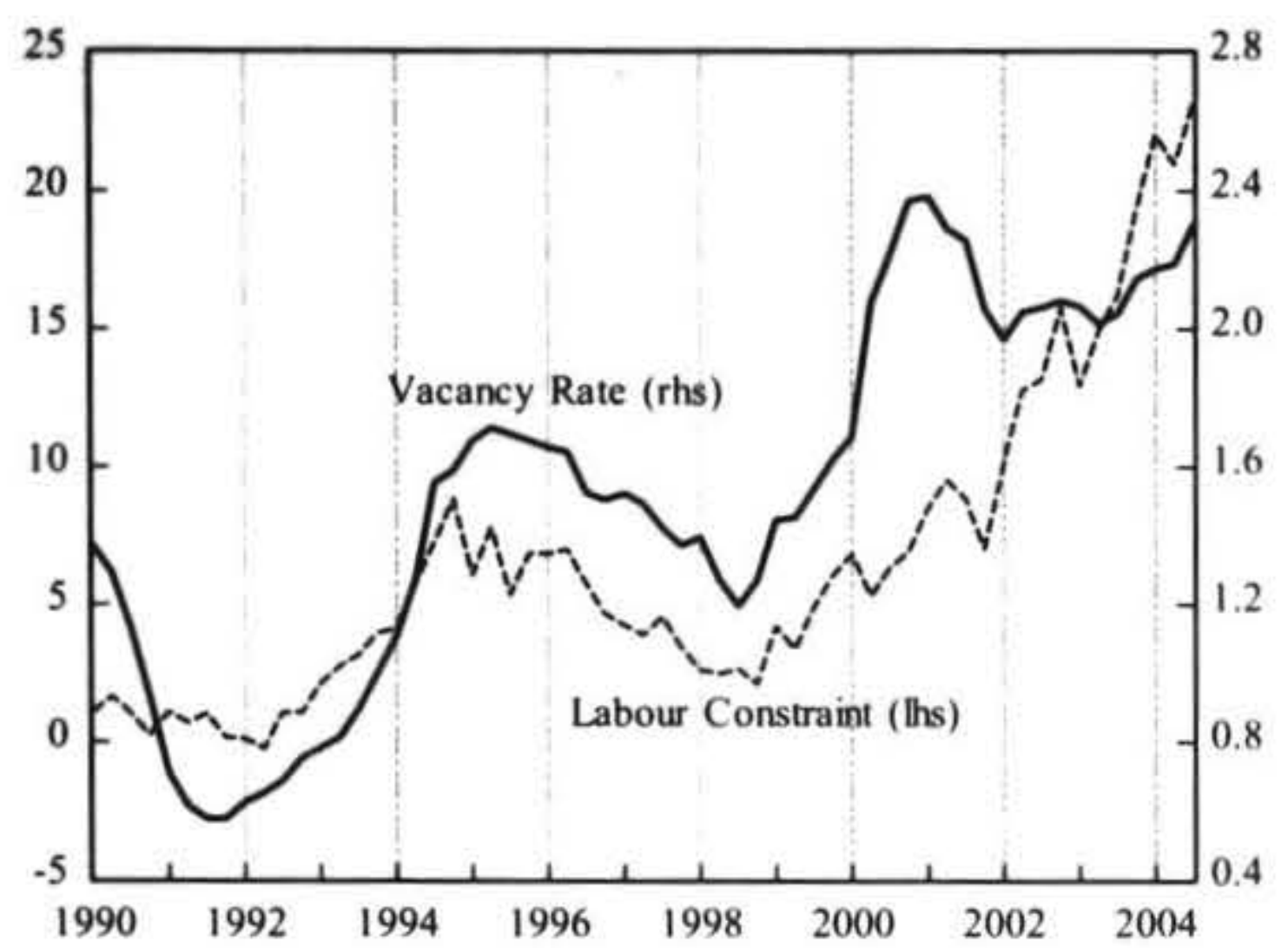

Sources: ANZ Bank (vacancies) and NZIER (labour).

A second QSBO question asks respondents: 'Is finding the skilled or specialist staff you want today compared to three months ago harder, the same or easier?'. One would expect a higher vacancy rate to be associated with greater difficulty in finding labour. This is confirmed in Figure 4 which plots the vacancy rate against the QSBO net balance of responses (that is, the percentage replying 'harder' less the percentage replying 'easier'). The correlations of finding skilled labour with the vacancy rate (with and without internet ads) are 0.89 and 0.82 , respectively. Unlike the relationship in Figure 3, the post2002 outcomes show somewhat greater conformity.

Finally, in this proxy vacancy discussion, consider the dynamic process illustrated in Figure 5 involving flows to and from vacancies. Job creation and quits are inflows into the stock of vacancies while matching or hiring is the outflow. The Household Labour Force Survey, through its ability to match respondents in adjacent surveys, provides stock-flow data in the spirit of Figure 5. Figure 6 illustrates this data for the March to June quarter 2004. (See Silverstone 2001 and Silverstone and Gorbey 1995 for further details on labour market gross flows in New Zealand).

\section{Figure 4: Finding Skilled Labour and Vacancy Rate 1990-2004}

Quarterly, March Years, Percent

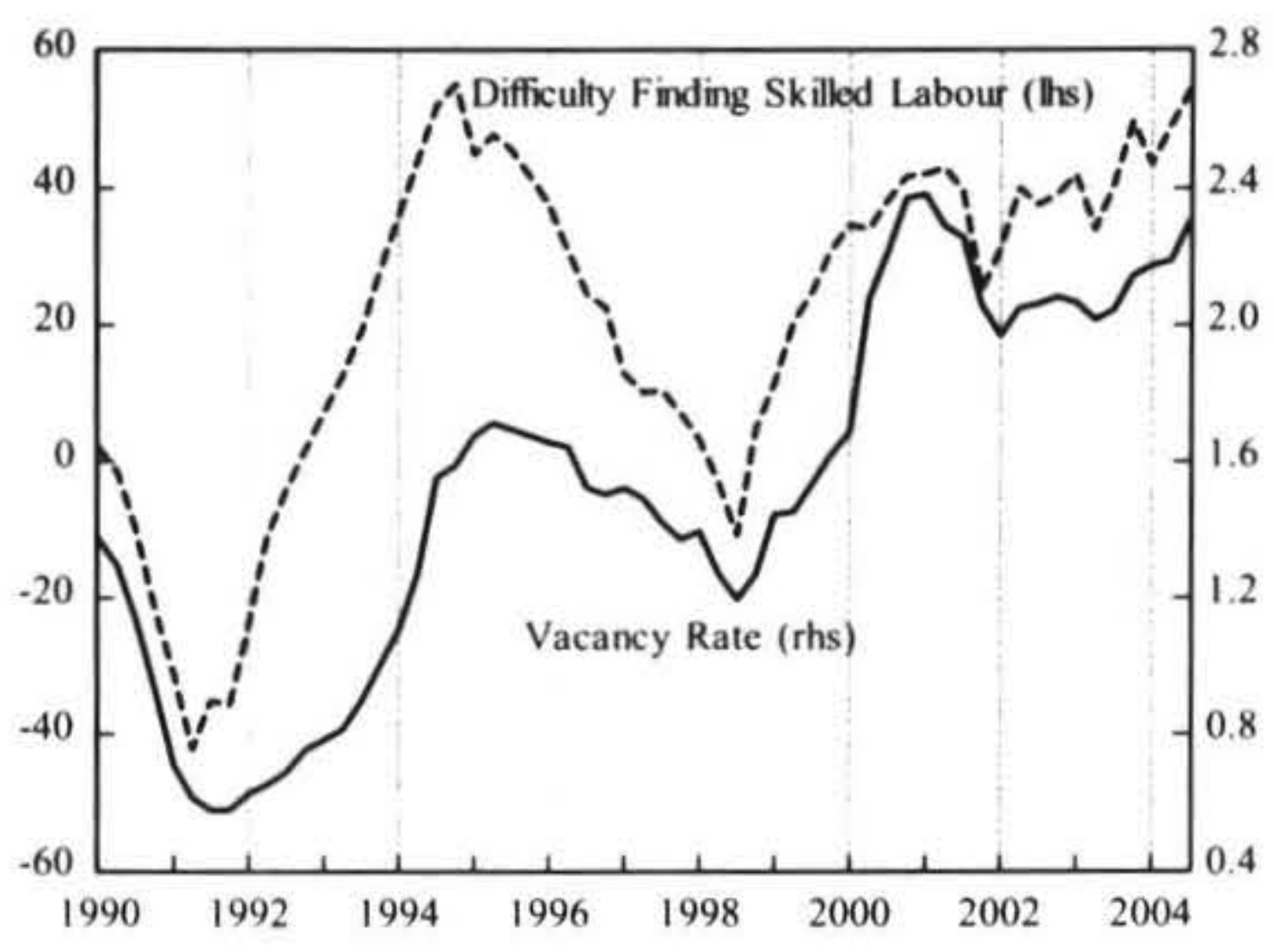

Sources: ANZ Bank (vacancies) and NZIER (labour)

From Figure 6, suppose the net flows between unemployment and employment (that is, $U E$ minus $E U$ ) are the only sources of new hiring and, therefore, vacancies filled. Figure 7 shows the relationship between the vacancy rate and the net hiring rate where the net hiring rate $(N H R)$ is defined as:

$$
N H R=\left(\frac{U E-E U}{U_{-1}}\right) 100
$$

$U E$ is the gross flow of labour from unemployment to employment, $E U$ is the flow from employment to unemployment and $U_{-1}$ is total unemployment in the previous quarter. Figure 7 shows a relatively strong relationship between the series with their upper and lower turning points typically coinciding. The correlations of the hiring rate with the vacancy rate (with and without internet ads) are 0.86 and 0.81 , respectively

\section{Figure 5: The Beveridge Curve and Hiring Frameworks}

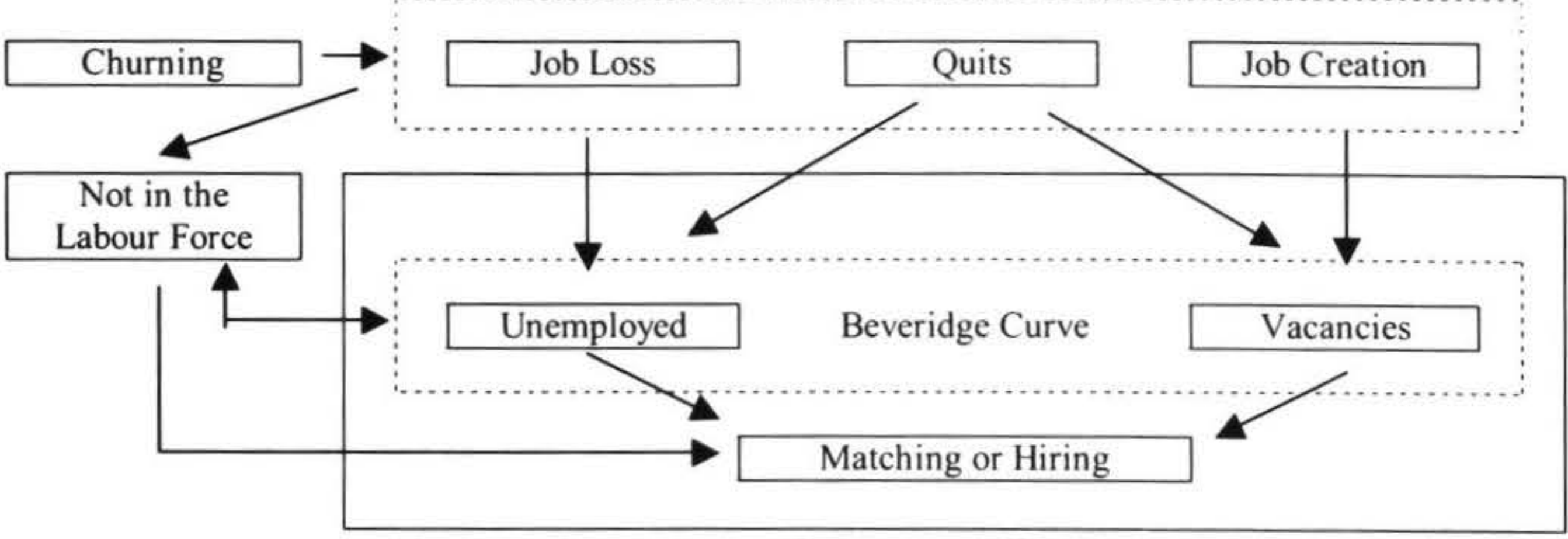

Source: Bleakley and Furher (1997, p.7) slightly modified. 
Figure 6. Gross Labour Market Flows in New Zealand

Males and Females, All Ages, Number, March to June 2004

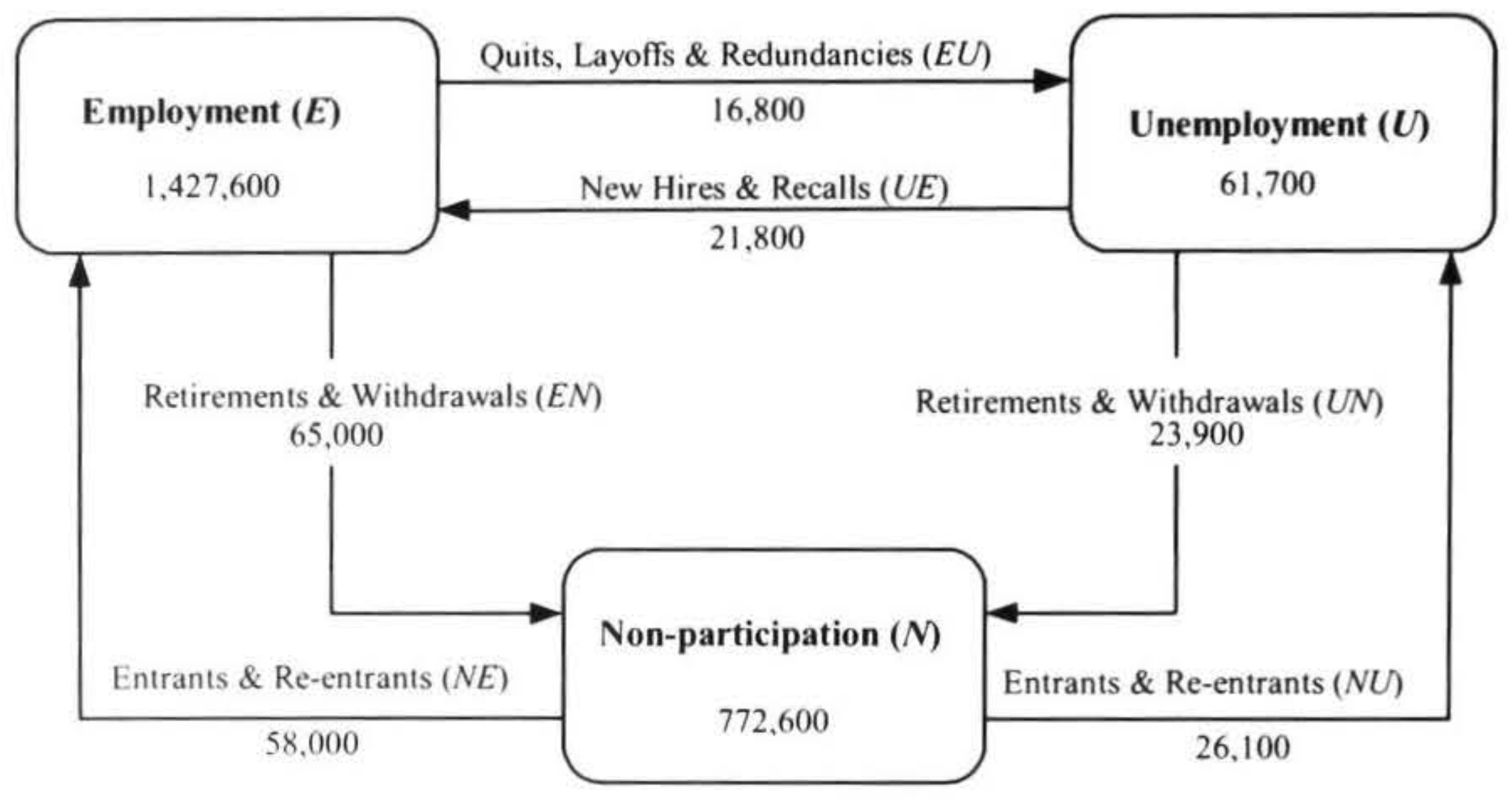

Sources: Statistics New Zealand and Silverstone (1995, 2001).

Figure 7: Hiring and Vacancy Rates 1990-2004

\section{March Years, Percent}

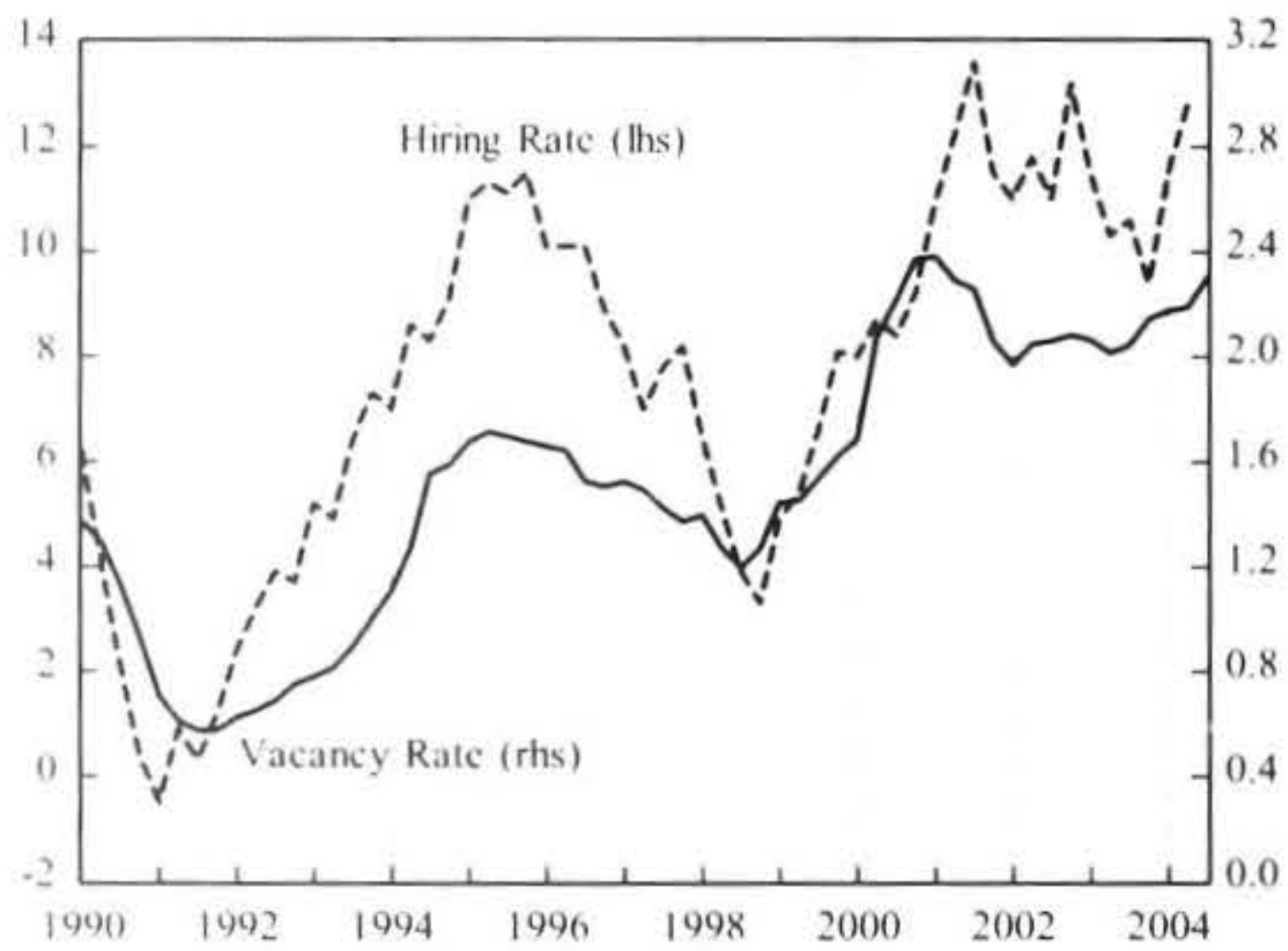

Sources: ANZ Bank (vacancies) and Stats NZ (hiring).

\section{Analytical Framework}

Our discussion this far has been mainly descriptive rather than analytical. Vacancy data feature prominently in at least two analytical frameworks: static Beveridge curve analysis (the study of the equilibrium or stock relationship between vacancies and unemployment) and dynamic job hiring or matching analysis. These frameworks are useful from several perspectives. From a policy perspective, better employment and activity outcomes could result from insights into the processes by which vacancies are created and notified and by how people are matched to jobs. From a forecasting perspective, the vacancy-unemployment relationship is helpful in interpreting labour market outcomes (Hall 2003).

From an academic perspective, the contributions of Abraham (1987), Blanchard and Diamond (1989) and Pissarides (1986), among others, have sustained an active Beveridge curve research programme. The attractiveness of this programme is due substantially to its underlying theoretical framework - the aggregate matching function for analysing macroeconomic frictions and policy options. (See Petrongolo and Pissarides 2001 for a major survey of the existence and stability of the aggregate matching function).

Figures 5 and 6 highlighted the fact that the labour market is characterised by stocks (such as the unemployed and vacancies) and by the flows to and from these stocks. Job losses, quits and net movements from not in the labour force are the main inflows into unemployment while job creation and quits generate vacancies. Job-to-job movements or 'churning' aside, new hiring is the outcome of a search and matching process involving the unemployed and vacant jobs.

The dynamics of the search and matching process, and the equilibrium nature of the Beveridge curve, can be illustrated more formally. Petrongolo and Pissarides (2001, p.392) and Wall and Zoega (2002, pp.258-59) are good examples of the contemporary approach based on the hiring or matching function. Adapting their approaches slightly, and following the usual practice of omitting job-to-job movements, let:

$$
H=m(w U, e V) \quad H_{U}, H_{V}>0
$$

where $H$ is the number of jobs matches or hires formed, $U$ the number of unemployed workers looking for work and $V$ the number of vacant jobs. Search intensity - or the choosiness - of workers and firms is represented by $w$ and $e$, respectively. The hiring function is assumed to be increasing in both $U$ and $V$, concave and with constant returns to scale. Using a Cobb-Douglas specification, and letting $A$ represent search intensities and other influences, the hiring function (equation 2) becomes:

$$
H=A U^{\alpha} V^{1-\alpha}
$$




$$
\ln H=A+\alpha \ln U+(1-\alpha) \ln V
$$

In equilibrium, the number of separations from unemployment $(S)$ equals the number of hires $(H)$. Substituting $S$ for $H$, and normalising by the size of the labour force $(L)$, equation 3 a becomes:

$$
\frac{S}{L}=A\left(\frac{U}{L}\right)^{\alpha}\left(\frac{V}{L}\right)^{1-\alpha}
$$

or, in log-linear form:

$$
\ln (s)=A+\alpha \ln (u)+(1-\alpha) \ln (v)
$$

where $s$ is the separation rate $(S / L), u$ the unemployment rate $(U / L), v$ the vacancy rate $(V / L)$ and $A$ is the intercept. With a fixed separation rate and intercept, equation (4b) yields an inverse relationship - the Beveridge curve between the vacancy rate and the unemployment rate. It could be estimated as:

$$
\ln \left(u_{t}\right)=a+b \ln \left(v_{t}\right)+e_{t} \quad b<0
$$

'Thus, the $U V$ curve can be interpreted - analogous to the theory of the firm - as an isoquant, which shows different combinations of inputs in order to produce a particular level of job matches' (Christl 1994, p.241).

The econometric literature is dominated by variations of the hiring or matching function (equation $3 \mathrm{~b}$ ) and the Beveridge curve (equation 5). For a convenient summary of the former, see Petrongolo and Pissarides 2001 and for the later see Christl 1992 (as reproduced in Tse et al. 2002). Before undertaking some preliminary New Zealand econometric work on equations ( $3 \mathrm{~b}$ ) and (5), we examine some descriptive aspects of the relationship between vacancies, unemployment and activity.

Figure 8 shows the vacancy and unemployment rates from 1990:1 to 2004:3. The vacancy rate (the ratio of job ads to the labour force) varies within a relative narrow band from 0.6 to 2.4 percent of the labour force with a mean of around 1.5 percent. On the other hand, the unemployment rate (the ratio of surveyed unemployment to the labour force) ranges from 4 to 11 percent with a mean of 7 percent.

The inverse relation between the vacancy and unemployment rates is clearly apparent in Figure 8. This is confirmed by the high correlation of -0.95 when internet ads are included in the vacancy rate and 0.90 when they are excluded. The coincidence of turning points is also apparent (see, for example, 1991, 1995, 1998 and 2001). A further characteristic is the relatively weak relationship since 2000 between the vacancy rate (excluding internet ads) and the unemployment rate. Whereas the unemployment rate fell by one third (from 6 percent to 4 percent) between 2000 and 2004, the vacancy rate (excluding internet ads) remained substantially unchanged at around 1.6 percent over the same period. This evidence is further support for combining internet and newspaper ads.
Quarterly, March Years, Seasonally Adjusted, Percent

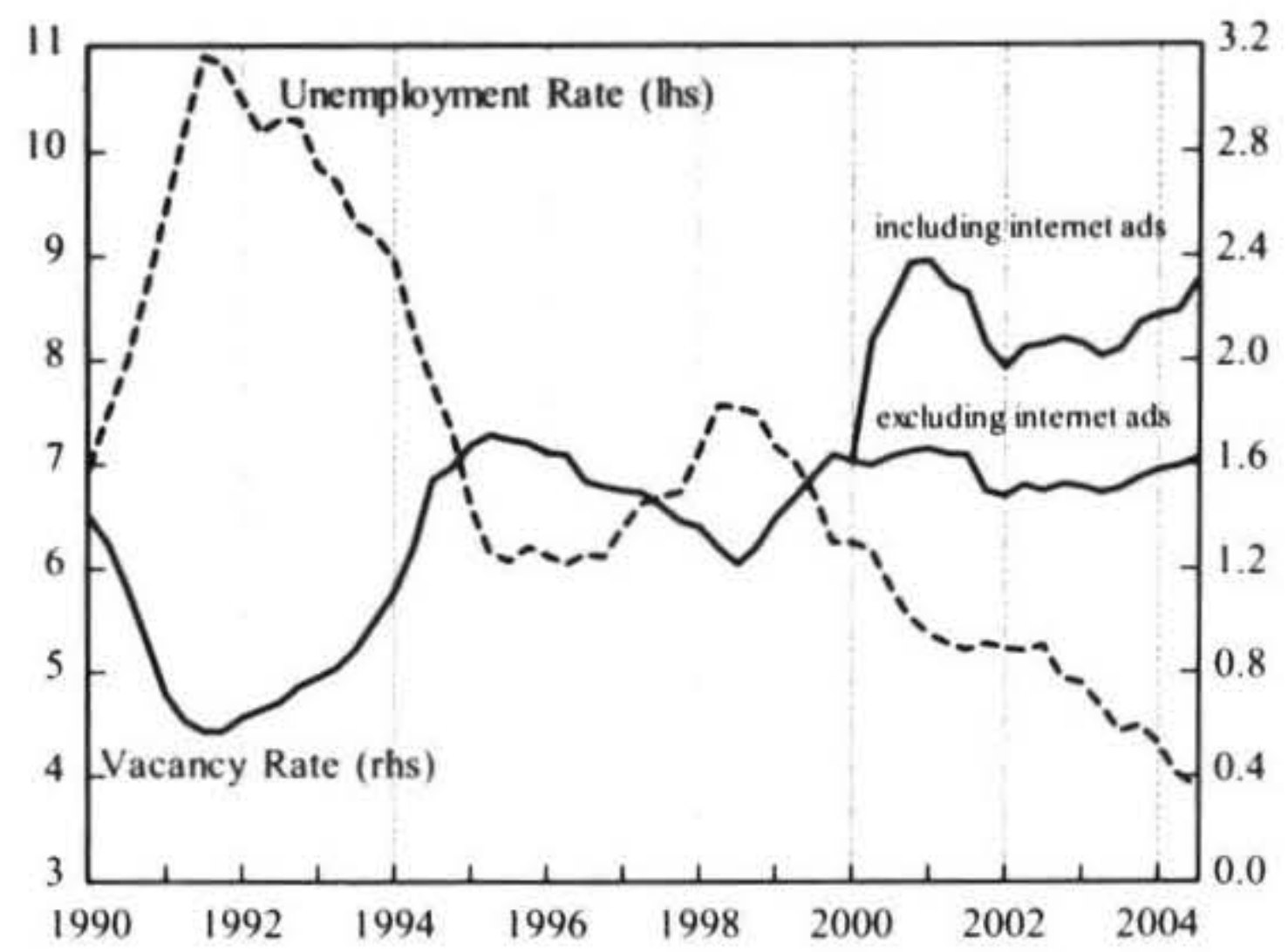

Sources: ANZ Bank (vacancies) and Stats NZ (labour).

Figure 9 is a Beveridge curve of the vacancy rate against the unemployment rate. (Textbooks, and many empirical studies, distinguish between novements along and shifts of the Beveridge curve to supposedly identify cyclical and structural changes, respectively. See, however, the cautions in Bowden 1980). There are several impressions from Figure 9. First, almost the entire period (19902004 ) is characterised by counter-clockwise looping. Secondly, the scatter appears to be linear or very slightly convex. The tendency towards linearity could be explained partly by the relatively short time series ( 15 years) and by aggregation. Thirdly, the Beveridge curve appears to have shifted to the left since 2001 .

\section{Figure 9: Vacancy \& Unemployment Rates 1990-04}

\section{Seasonally Adjusted, September Years, Percent}

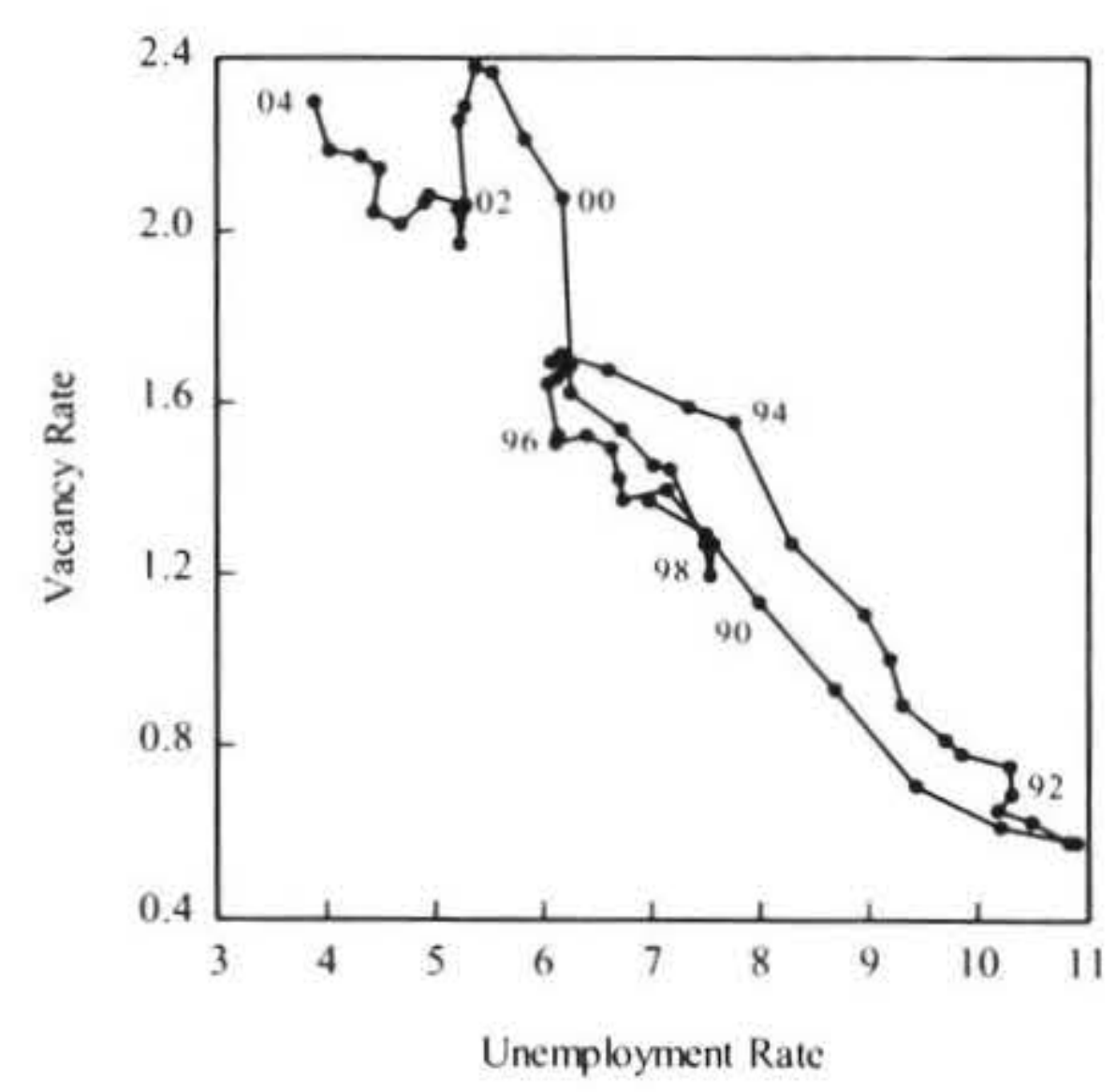

Sources: ANZ Bank (vacancies) and Stats NZ (labour).

Do changes in the unemployment rate leads changes in the vacancy rate or conversely? Impulse response functions, with two lags between the unemployment and vacancy rates suggest, marginally, that vacancies lag the unemployment rate. This weak finding is not surprising given that both variables are endogenous. 
Finally, Figure 10 illustrates the link between real GDP growth and vacancy growth. The correlation is 0.67 . Overall, periods of strong economic growth correspond to periods of strong vacancy growth, and conversely.

\section{Figure 10: GDP \& Vacancy Growth Rates 1991-04}

Quarterly, March Years, Percent

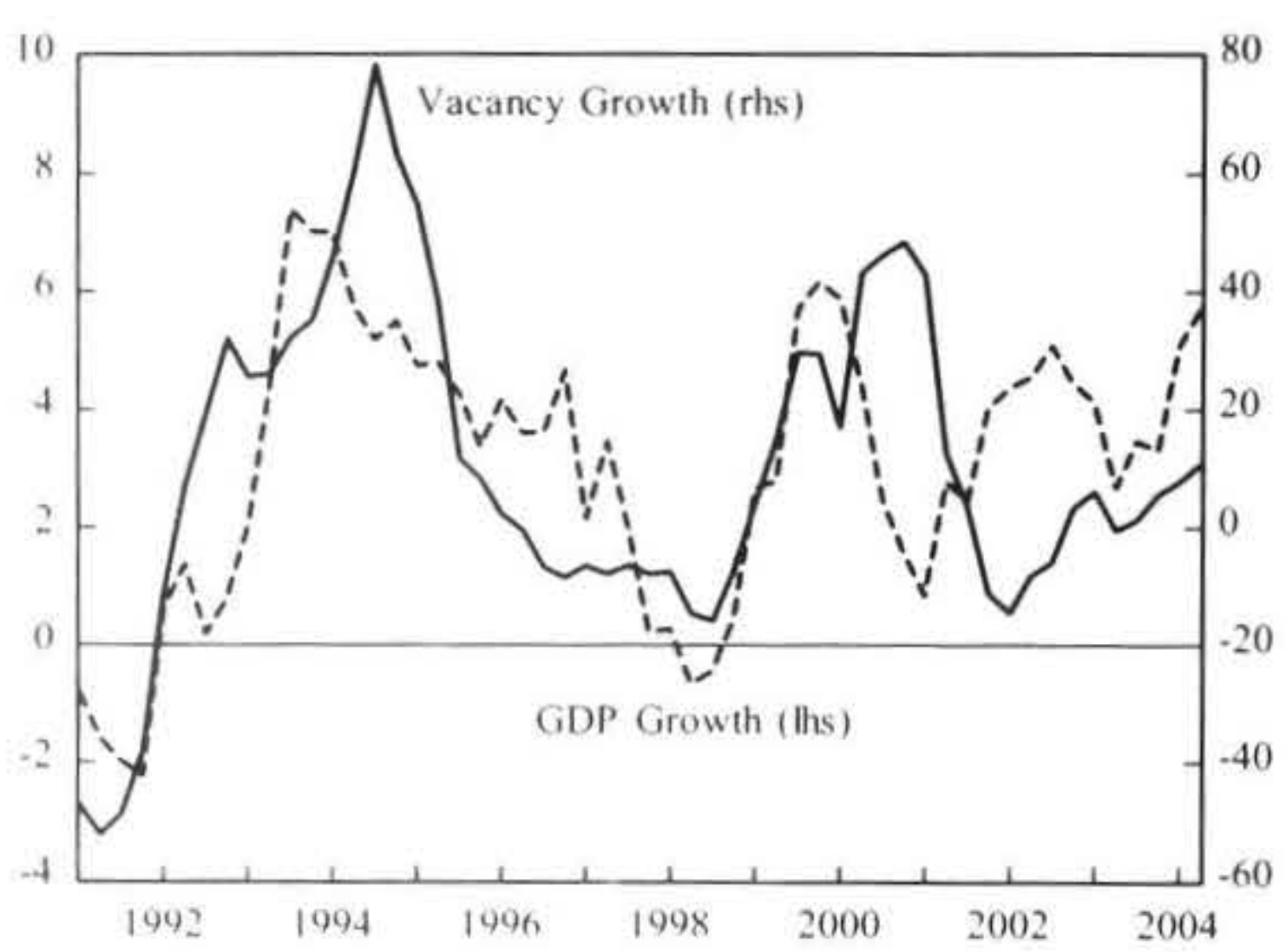

Sources: ANZ Bank (vacancies) and Stats NZ (GDP).

\section{Estimation}

We now undertake some initial econometric work on the Beveridge curve (equation 5) and the hiring function (equation 3b). Previously published Beveridge curve work using New Zealand data includes Chapple (1995), Chapple el al. (1996) and Nickell el al. (2001).

\section{Bereridge Cune}

Although unemployment and vacancy rates are bounded in the long run, and therefore mean-reverting, they may not be stationary over shorter periods. Before running regressions involving vacancy and unemployment rates, we should test for unit roots in these variables. This should determine whether OLS regression is appropriate, at least initially.

Using the augmented Dickey-Fuller (ADF) approach, our prefiered equation for the unemployment rate $(u)$ is:

$$
\Delta u_{t}=\alpha_{0}+\beta_{0} u_{t-1}+\delta t+\varepsilon_{0}
$$

and, for the vacancy rate (v),

$$
\Delta v_{t}=\alpha_{1}+\beta_{1} v_{t-1}+\delta t+\varepsilon_{1}
$$

A linear time trend is represented by $t$ and the error term by $\varepsilon$. The results (available on request from the author) indicate that over the period 1990-2004, the unemployment rate has a unit root at all critical values and is therefore a non-stationary series. The same conclusion is accepted at the one and five percent critical values for the vacancy rate but not, perhaps, at the 10 percent critical value. A similar conclusion is reached in the more extensive unit root testing by De Francesco (1999) on Australian vacancy and unemployment data.

Given this unit root outcome, the Johansen cointegration test indicates cointegration at the five percent level assuming an intercept and a linear deterministic trend in the cointegrating equation. This result allows us to run regressions between the unemployment rate and the vacancy rate. Given the somewhat marginal nature of the unit root and cointegration tests, however, regressions in the differences of the unemployment and vacancy rates were also explored.

The basic Beveridge curve specification is:

$$
\ln \left(u_{t}\right)=a-b \ln \left(v_{t}\right)+z_{t}+e_{t}
$$

where $u$ and $v$ are seasonally adjusted unemployment and vacancy rates, respectively, and $e_{t}$ is an error term. Other potential influences (for example, mismatch and the participation rate) are represented by $z$. The ordering of the endogenous variables is, on this occasion, from $v$ to $u$ and the data period is $1990: 1$ to $2004: 3$.

Although both log-linear and linear equations involving just $u$ and $v$ fitted well overall, the residuals show periods of persistent under and over prediction of the unemployment rate. This outcome suggests, among other things, omitted variables or shift influences $(z)$. Candidates include mismatch, changes in the participation and labour force growth rates, labour market churning and turnover, the choosiness of firms and workers, the output gap, real wages and profits and time.

For illustrative purposes, equation (8) reports a result with just one $z$ influence, namely, the participation rate (p). A linear estimation is preferred slightly to the loglinear specification in equation (7). Brackets enclose $t$ statistics.

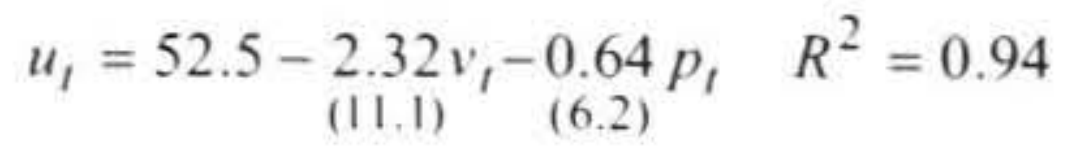

Equation (8) has the expected signs and significance. The standard error of the regression is 0.45 percent compared to the mean of the unemployment rate of 7 percent. Figure 11 is a chart of the actual and fitted series and the residuals. One would expect to improve on the outcome in equation (8) with further consideration of other shift influences and other specifications.

We now turn briefly to some preliminary econometric insights from regional data. With the aggregated data, there are 59 quarterly observations between 1990:1 and 2004:3. With regional cross-section data available over the same period from Auckland, Wellington and Christchurch newspapers, there are 177 observations. As a result, pooled time series, cross-section data offers many regression possibilities including cross-section weighting, common and cross-section specific intercepts and coefficients. 
Figure 11: Beveridge Curve Regression 1990-04

Equation (8), Quarterly, March Years

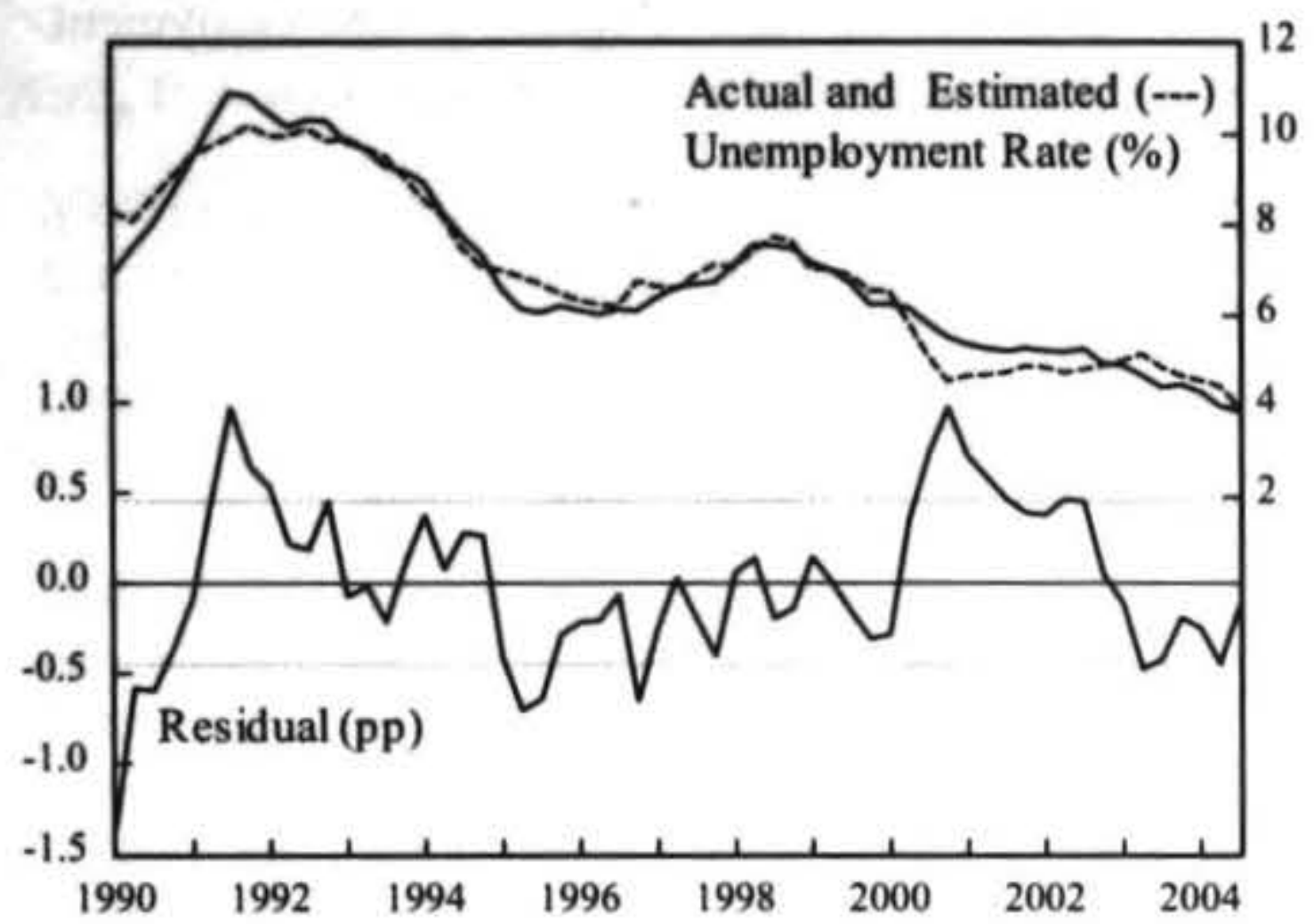

Sources: ANZ Bank (vacancies) and Stats NZ (GDP).

Figure 12 shows scatter charts of the unemployment ratevacancy rate $(u v)$ relationship for Auckland, Wellington and Christchurch. (Internet ads are excluded). Auckland and Christchurch are relatively similar whereas Wellington appears to have no clear macroeconomic relationship between vacancies and unemployment. These observations are confirmed tentatively in Table 2 where, for reasons of space, results for an equation (8) specification only are reported. The $u v$ relationship is significantly inverse for Auckland and Christchurch but absent for Wellington. The participation rate is significant for Wellington and Christchurch, but not for Auckland.

Table 2: Regional Regressions 1990-2004

$$
u_{i t}=a-b v_{i t}-p_{i t}+e_{i t}
$$

\begin{tabular}{|c|c|c|c|}
\hline $\begin{array}{c}\text { Unemployment } \\
\text { Rate }(u)\end{array}$ & $a$ & $\begin{array}{l}\text { Vacancy } \\
\text { Rate }(v)\end{array}$ & $\begin{array}{c}\text { Participation } \\
\text { Rate }(p)\end{array}$ \\
\hline Auckland & 13.5 & $\begin{array}{c}-3.22 \\
(9.6)\end{array}$ & $\begin{array}{c}0.02 \\
(0.13)\end{array}$ \\
\hline Wellington & 73.0 & $\begin{array}{c}-0.17 \\
(0.31)\end{array}$ & $\begin{array}{c}-0.97 \\
(6.0)\end{array}$ \\
\hline Christchurch & 28.5 & $\begin{array}{c}-2.14 \\
(4.3)\end{array}$ & $\begin{array}{c}-0.29 \\
(3.6)\end{array}$ \\
\hline
\end{tabular}

Sources: ANZ Bank (vacancies) and Stats NZ (labour).

\section{Hiring Function}

The basic hiring specification is:

$$
\ln \left(h_{t}\right)=A+\alpha \ln \left(u_{t-i}\right)+(1-\alpha) \ln \left(v_{t-i}\right)+e_{t}
$$

where $h$ is the net hiring rate from unemployment as defined in equation (1), $u$ and $v$ are seasonally adjusted unemployment and vacancy rates, respectively, and $e_{t}$ is an error term. The estimation period is 1990:1 to 2004:2. Equation (9) illustrates an unrestricted outcome (where brackets enclose $t$-statistics) while Figure 13 is a chart of the actual and fitted series and the residuals.

$$
\ln h_{t}=\underset{(15.1)}{0.61} \ln u_{t}+\underset{(13.1)}{1.94} \ln v_{t} \quad R^{2}=0.62
$$

For an initial hiring equation - dealing with only $U E$ and $E U$ flows and with no other variables, such as mismatch and demographics - this outcome is promising. The variables are significant and have their expected values although constant returns to scale is not apparent. Restricting the coefficients on $u$ and $v$ to sum to unity produces some outcomes yet to be explained.

Figure 13: Hiring Function Regression 1990-04 Equation (9), Quarterly, March Years

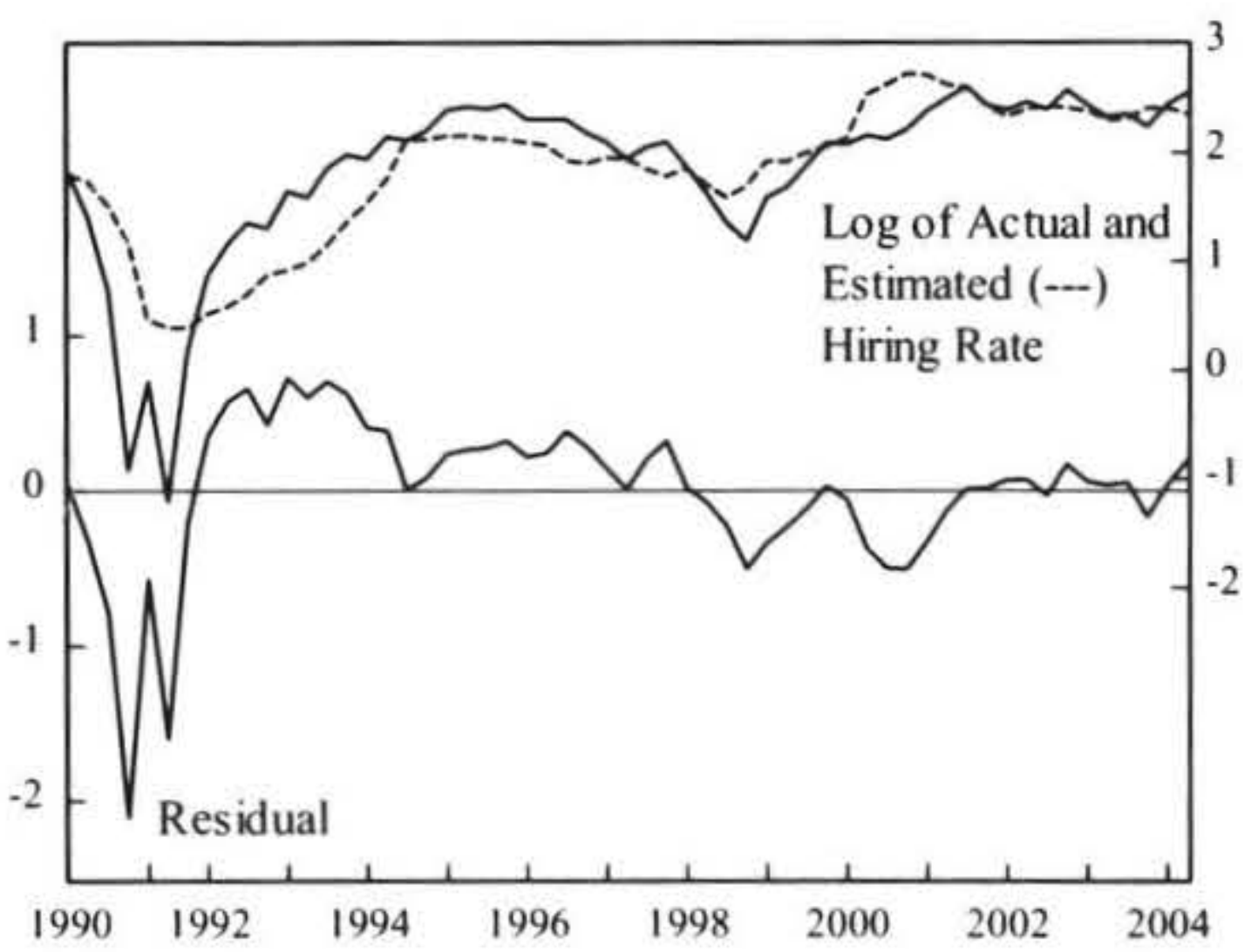

Sources: ANZ Bank (vacancies) and Stats NZ (labour).

Figure 12: Regional Vacancy and Unemployment Rates 1990-2004 Quarterly, Seasonally Adjusted, Percent
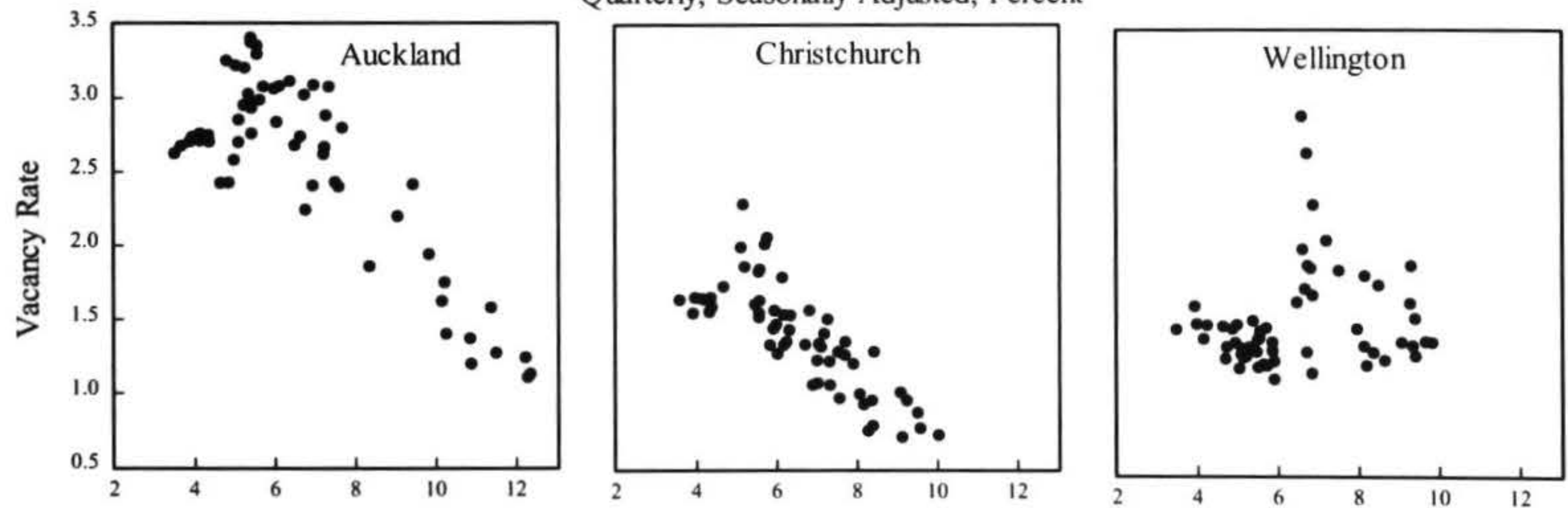

Sources: ANZ Bank (vacancies) and Stats NZ (labour).

Unemployment Rate 


\section{Future Research}

Future work could include a more extensive analysis of the time series properties and regional characteristics of the job ads series, more extensive unit root and cointegration analysis, testing for Beveridge curves shifts and increasing returns and undertaking international comparisons. More extensive analysis of the hiring function should also be a significant component of future work. Ultimately, it would be worthwhile determining the impact of policy and non-policy changes on New Zealand Beveridge curves and hiring functions.

\section{Conclusions}

This paper has considered some descriptive, analytical and empirical aspects of the ANZ Bank job advertisement series. The overall purpose has been to renew interest in the role of both the vacancy rate and the hiring rate in the assessment of labour market conditions. The paper has therefore included insights from the job ads series itself, regional differences, selected proxy series and the analytics of the Beveridge curve and hiring functions. The importance of internet ads and their integration with newspaper advertisements was also highlighted.

The econometric work included some basic unit root testing and cointegration and some initial Beveridge Curve and hiring regressions. We found, among other things, that New Zealand's Beveridge curve (over the period 1990-2004) could well be linear and that shift influences and regional differences are likely to matter. The hiring function work appears promising.

\section{Acknowledgements}

I am grateful to the ANZ Banking Group (and to its Wellington-based Economics Department in particular) for making the Bank's monthly unadjusted job ads data available for this project. I am also grateful to the NZIER and the Department of Labour for data assistance. The usual disclaimer applies.

\section{References}

Abraham, K.G. (1987). Help-Wanted Advertising, Job Vacancies, and Unemployment. Brookings Papers on Economic Activity (1) 207-48.

ANZ Banking Group, New Zealand, Economics Department (1990-) ANZ Job Ads, monthly. Web: [www.anz.com/nz/tools/newslibrary.asp?ANZ_ Job_Ads].

Blanchard, O.J. and Diamond, P. (1989). The Beveridge Curve. Brookings Papers on Economic Activity (1) 1-76.

Bleakley, H. and Fuhrer, J.C. (1997). Shifts in the Beveridge Curve, Job Matching, and Labor Market Dynamics. New England Economic Review, 3-19.
Bowden, R.J. (1980). On the Existence and Secular Stability of $u-v$ Loci. Economica, 47, 35-50.

Chapple, S. (1995). Scepticism on NAIRU-based Explanations of New Zealand's Unemployment. NZIER Working Paper 95/8, 28pp.

Chapple, S., Harris, R. and Silverstone, B. (1996). Unemployment. In B. Silverstone, A. Bollard and R. Lattimore (eds) A Study of Economic Reform: The Case of New Zealand. Amsterdam: NorthHolland.

Christl, J. (1992). Structural Unemployment in Austria. In W. Franz (ed.) Structural Unemployment. Heidelberg: Physica-Verlag.

Christl, J. (1994). Mismatch Unemployment in Austria. In J. Muysken (ed.) Measurement and Analysis of Job Vacancies: An International Comparison. Aldershot: Avebury.

De Francesco, A.J. (1999). The Relationship between Unemployment and Vacancies in Australia. Applied Economics, 31, 641-52.

Department of Labour, Labour Market Policy Group (2003). Identification of a Survey Option for the Collection of Vacancy Information in New Zealand, January, 106pp.

Hall, R.E. (2003). Modern Theories of Unemployment Fluctuations: Empirics and Policy Applications. American Economic Review, 93, 145-50.

Hicks, J. and Chin, F.E. (1984). The Relationship between Unemployment and Vacancies in New Zealand. Massey University Massey Economic Papers B8405. March, 33pp.

Nickell, S., Nunziata, L., Ochel, W. and Quintini, G., (2001). The Beveridge Curve, Unemployment and Wages in the OECD from the 1960s to the 1990s. Centre for Economic Performance Discussion Paper 0205, July, 75pp.

Petrongolo, B. and Pissarides, C.A. (2001). Looking into the Black Box: A Survey of the Matching Function. Journal of Economic Literature, 39. 390-431.

Pissarides, C.A. (1986). Unemployment and Vacancies in Britain. Economic Policy, 3, 499-559.

Silverstone, B. (2001). Some Aspects of Labour Market Flows in New Zealand 1986-2001. University of Waikato, Working Papers in Economics 2/01, November, 24pp. Available from author or Web: [ftp://mngt.waikato.ac.nz/RePec/wai/econwp/0102 .pdf].

Silverstone, B. and Gorbey, S. (1995). Unemployment Dynamics in New Zealand. In P.S. Morrison (ed.) Labour. Employment and Work in New Zealand 1994, Wellington: Victoria University of Wellington. 
Tse, C.Y., Leung, C.K.Y. and Chan, W.Y.F. (2002). Unemployment and Vacancy in the Hong Kong Labour Market. Applied Economics Letters, 9, 221-29.

Wall, H.J. and Zoega, G. (2002). The British Beveridge Curve: A Tale of Ten Regions. Oxford Bulletin of Economics and Statistics, 64, 257-76.
Zagorsky, J.L. (1993). Job Vacancies in the United States and Canada. Journal of Economic and Social Measurement, 19, 305-19.

Zagorsky, J.L. (1998). Job Vacancies in the United States: 1923 to 1994. Review of Economics and Statistics, 80, 338-45. 